\author{
Viviam Unás \\ Universidad Icesi, Colombia \\ vsunas@icesi.edu.co
}

\title{
Nuevos repertorios tecnológicos y movimientos sociales: el caso de la Asociación Indígena del Norte del Cauca (ACIN)
}

New Technological Repertoires and Social Movements: the
case of the Northern Cauca Indigenous Association (ACIN)

Novos Repertórios Tecnológicos e Movimentos Sociais: o caso da Associação Indígena do Norte de Cauca (ACIN)

Artículo de reflexión recibido el 24/09/2010 y aprobado el 02/11/2010 



\begin{abstract}
Resumen
Este artículo pretende elaborar algunas reflexiones sobre el modo en que la WEB está siendo usada como escenario en el que se producen luchas sociales y se pactan alianzas políticas que, de fondo, estarían reconfigurando la idea de acción colectiva y movimiento social. Se hará énfasis en la forma en que algunos movimientos sociales, en particular el movimiento indígena del Norte del Cauca, han usado la WEB para ampliar sus repertorios de acción, sus objetos de lucha y los actores que a ésta se suman. Sostenemos que, para ello, los movimientos sociales, aún sin proponérselo, han convertido al trabajo de gestión de vínculos y la actitud conexionista -que Boltanski y Chiapello (2002) ${ }^{1}$ atribuyen al trabajador en mercados laborales flexibles- en recursos centrales del ejercicio militante.
\end{abstract}

Palabras clave: Acción Política, Nuevos Repertorios Tecnológicos, Subpolítica

\begin{abstract}
The purpose of this article is to present some reflections on the way in which the Internet is being used as a stage on which social struggles are fought out and political alliances are formed, which would ultimately reshape the ideas of collective action and social movement. It places emphasis on the approach of some social movements (especially of the indigenous movement in the northern Cauca region) to using the web to expand their repertoires of actions, their objectives for struggle, and the number of stakeholders who join their initiatives. In this respect, we claim that social movements, even without intending to do so, have turned the efforts to establish links and a connectionist attitude, which Boltanski and Chiapello (2002) attributed to workers in flexible labor markets, into core resources of the militant practice.
\end{abstract}

Key words: Political Action, New Technological Repertoires, Subpolicy

\title{
Resumo
}

Este artigo pretende elaborar algumas reflexôes sobre a maneira como a Internet está sendo usada como o cenário em que se produzem lutas sociais e se acordam alianças políticas que, neste contexto, seria reformular a idéia da açáo coletiva e do movimento social. Será dada ênfase ao modo como alguns movimentos sociais, em particular o movimento indígena do Norte de Cauca, usaram a Internet para expandir seu repertório de ação, seus objetivos de luta e os atores que se juntam a essa. Argumentamos que, para fazê-lo, os movimentos sociais, ainda que sem querer, converteram o trabalho de gestáo de vínculos e a atitude conexionista - que Boltanski e Chiapello (2002) atribuem ao trabalhador em mercados laborais flexíveis - em recursos centrais do exercício militante.

Palavras-chave: Ação Política, Novos Repertórios Tecnológicos, Subpolítica

1 Vale la pena aclarar que se han apropiado rasgos generales de la teoría expuesta por los autores para repensarlos en el contexto del campo político. Esta operación puede implicar una lectura un tanto infiel de los argumentos de los autores, licencia que nos hemos permitido en virtud de la comprensión panorámica del fenómeno que nos interesaba abordar. 



\section{A modo de introducción}

- El 11 de marzo de 2004, Al Qaeda efectuó uno de los peores atentados terroristas de la historia de España, en retaliación por la participación de ese país en la invasión a Irak. Presuntamente, los medios españoles y el gobierno de Aznar intentaron ocultar información que responsabilizaba del atentado a Al Qaeda y pretendieron sugerir que éste había sido obra de ETA. El 13 de marzo, sin embargo, dos días después, los ciudadanos espańoles protagonizaron manifestaciones espontáneas que terminaron inclinando la balanza en las elecciones generales a favor de Rodríguez Zapatero (PSOE). Muchas de estas manifestaciones fueron gestadas a través de mensajes de telefonía celular.

- La minga que arribó a la Universidad del Valle el 23 de octubre de 2008, compuesta por más de 30.000 indígenas provenientes en su mayoría del Norte del Cauca, en Colombia, fue trasmitida minuto a minuto a través de la página WEB Nasanet (www.nasaacin.org), bajo la responsabilidad del Tejido de Comunicaciones y Relaciones Externas para la Verdad y la Vida de la ACIN (Asociación de Cabildos Indígenas del Norte del Cauca). Como sucedió con el Ejército Zapatista de Liberación Nacional, en México, acciones online como ésta han permitido al movimiento indígena no sólo vincularse con otros movimientos sociales e indígenas internacionales, sino convertirse en difusores estratégicos de información que termina actuando en su defensa. Prueba de ello lo constituye el video denominado "Pruebas contundentes del uso de armas por parte de la fuerza pública", que hacia finales de octubre del 2008 grabaron reporteros indígenas, en el que se observa a miembros de la fuerza pública disparando contra la población asentada en el Norte del Cauca. El video en mención fue enviado por el Tejido de Comunicaciones a CNN para su trasmisión y fue publicado en la página de la ACIN. El 2 de noviembre de 2008, el presidente Uribe debió admitir públicamente -en contra de lo que había asegurado semanas antes-que los militares habían usado armas de fuego en contra de la población.

- En su libro Multitudes Inteligentes (2002), Howard Rheingold describe dos fenómenos que guardan similitudes con los anteriores: las manifestaciones que contribuyeron al derrocamiento de Estrada, en Filipinas, en enero del ańo 2000 y las movilizaciones de Seattle en noviembre y diciembre de 1999 contra la Organización Mundial del Comercio; organizadas ambas con la participación de teléfonos móviles y medios en red. ${ }^{2}$

$2 \mathrm{Al}$ respecto, puede mencionarse también un ejemplo local: la marcha de febrero de 2008 en Colombia, y otros países, contra las FARC, originada en Facebook y rápidamente coaptada y promovida por otros medios masivos como la televisión y la radio. 
Los ejemplos señalados parecen tener en común por lo menos cuatro elementos. En primer lugar, se trata, en la mayoría de los casos, de acciones políticas cristalizadas por lo que reconocemos como sociedad civil, al margen de las instituciones tradicionales de la política. En segundo lugar, con excepción quizá de la minga indígena promovida por la ACIN, se trata de manifestaciones más o menos espontáneas, agenciadas no desde un único movimiento central sino desde multiplicidad de grupos e individuos aparentemente aislados. En tercer lugar, nótese que en todos los ejemplos descritos se emplearon nuevos repertorios tecnológicos que favorecieron tanto la internacionalización de sus objetivos como la coordinación de acciones en tiempo real, bajo lógicas de desanclaje (Giddens, 1999) propias de la relación que, entre tiempo y espacio, nos propone la WEB. Por último, debe resaltarse que si bien en todos los casos se alude a acciones políticas, éstas buscaban metas de corto plazo -como hacer visibles situaciones indeseables, para el caso de la ACIN y las protestas contra Aznar, por ejemplo, o la articulación de variadas demandas sociales para el caso de las movilizaciones de Seattle-, que no necesariamente invitaban a la toma o búsqueda calculada del poder central.

En resumen, sostendremos en este documento, a modo de hipótesis, que estos ejemplos estarían nombrando formas de subpolítica (Beck, 2001) o política menor (Lazzarato, 2006), que se organizan en red y en tiempo real y que son agenciadas por individuos y movimientos conexionistas. Intentaremos para ello retomar algunos de los desarrollos que Boltanski y Chiapello (2002) establecen en el capítulo II de su libro El Nuevo Espíritu del Capitalismo, denominado "La Formación de la Ciudad por Proyectos". Si bien los autores se centran en la idea de individuos conexionistas como aquellos hábiles para propiciarse vínculos que favorecen su integración y permanencia en mercados de trabajo flexibles, sostendremos que la actitud conexionista es también atribuible a los modos de operación de ciertas iniciativas políticas que, con la participación de nuevos repertorios tecnológicos, se constituyen coyunturalmente como acciones vigorosas en formas de política por proyectos.

\section{Sobre los nuevos repertorios tecnológicos como ambientes}

Para caracterizar a los nuevos repertorios tecnológicos -NRT-, y con ello a sus cualidades y potencialidades políticas, conviene atender una versión de tecnología que supere los usuales determinismos tecnológicos y sociales. Los primeros, proponen que los artefactos imponen formas de actuar y establecen relaciones de dominación que, en ocasiones, no han sido previstas por sus productores. Las tecnologías gozarían entonces no sólo de un desmedido poder sino, también, 
de una peligrosa autonomía. Herederas de esta idea son algunas de las tramas que atraviesan los textos de ciencia ficción, desde los más tecnófobos hasta los más optimistas: desde el engendro del Doctor Frankestenstein, que se vuelve en contra suya, pasando por las máquinas inteligentes de Matrix, hasta las visiones de cyborgs sentimentales, que proliferan en la cinematografía de las últimas décadas. Las posturas que se inscriben en determinismos tecnológicos sugieren que, frente a los artefactos, los individuos tienen dos alternativas: la adaptación y la apropiación -como reiteradamente se le invita a hacer a la Escuela frente a las denominadas Tecnologías de la Información y la comunicación (TIC) - o la resistencia-como en el caso de las acciones que sectores proletarios emprendieron contra las máquinas, a comienzos del capitalismo industrial.

Por otro lado, los determinismos sociales, proponen que los artefactos son neutros y que su poder depende del modo en que los grupos sociales los regulen y apropien. Los determinismos sociales suelen ser frecuentes en la imagen academicista de la tecnología. La literatura en CTS suele concebir que existen por lo menos dos "imágenes" (González, et al., 1996) o representaciones sociales de la tecnología: la artefactual y la imagen academicista. En la primera, la tecnología se entiende como un conjunto de artefactos, en la segunda, como una aplicación de la ciencia que puede o no materializarse en artefactos concretos. En tanto se trata de ciencia aplicada, la imagen academicista plantea que la tecnología no es responsable de sus efectos y que, por el contrario, es tan neutral y objetiva como la ciencia. Así, la responsabilidad de los impactos nocivos del desarrollo tecnocientífico, deben recaer en los usos y las formas en que la sociedad se apropie de los conocimientos científicos y de los procesos de tecnificación.

Dos autores nos presentan perspectivas distintas a las deterministas: Winner (2001) y Latour (1998). En particular el primero seńala el modo en que ciertos artefactos contienen cualidades políticas, que provienen de sus procesos de diseño y producción, pero que no son enteramente calculados o conscientes. Por tanto, los artefactos establecerían formas de distribución del poder y autoridad que operan independientemente de la voluntad de los "usuarios" y productores y que terminan, sino imponiendo, por lo menos disponiendo su uso. A modo de ejemplo podríamos señalar el panóptico de Foucault pero, también, la máquina industrial que, en sí misma, propuso formas de racionalización del trabajo e introdujo transformaciones sobre los modos de producción y al consumo que revolucionaron el mundo occidental de una forma difícilmente predecible. En este sentido, los artefactos no serían neutros. Sin embargo, ello no implica que su poder sea ilimitado y predecible. Al respecto, Latour (1998) invita a la sociología a examinar la relación entre sociedad y tecnología como una relación inesperada 
de moldeamiento mutuo. Escobar (2005), empleará la idea de emergencia, para nombrar estas formas no esperables, no pre-determinadas, y por ello novedosas, de relaciones entre individuos, movimientos sociales y tecnología. Ambos autores coinciden en señalar que las acciones y obras que emergerían de esta relación no serían explicables exclusivamente por las cualidades de los artefactos, pero tampoco por la acción de los individuos, lo que nos obliga a comprender el modo en que se encuentran sociedad y tecnología, y la forma en que las cualidades de una y otra modelan cambios y continuidades sociales. Es esta perspectiva-que se centra más en las "relaciones" que en los efectos y apropiaciones, como en su momento nos lo propusieron los estudios funcionalistas e interaccionistas de los medios de comunicación- la que emplearemos en este documento para comprender los alcances de la creatividad política y tecnológica de ciertos movimientos sociales, en particular del movimiento indígena del Norte del Cauca.

Efectuada esta precisión, nos corresponde comprender a qué hacemos referencia cuando hablamos de nuevos repertorios tecnológicos (NRT), en especial porque, como se habrá notado, evitamos emplear la idea de Tecnologías de la Información y la Comunicación (TIC), frecuentemente usada para nombrar el conjunto de máquinas y herramientas que configuran el entorno tecnológico contemporáneo. Como NRT estamos agrupando, bajo una misma categoría, a artefactos que comprenden ciertas características comunes. En primer lugar, tienen similares fundamentos tecnológicos, 3 lo que implica que se trata de tecnologías que convergen y se integran, al punto que los desarrollos de una determinada rama -por ejemplo, de la microelectrónica- terminan afectando a las otras. Esta capacidad de integración se hace visible para el usuario común en la posibilidad de usar el ordenador como pantalla televisiva y radio, y el teléfono celular como ordenador personal y cámara fotográfica.

Por otro lado, se trata de artefactos que, desde la perspectiva de Virilio (1999), favorecen la coordinación de acciones en tiempo real. Esto es, acciones que se pactan online, desancladas de los condicionamientos y restricciones que exige el tiempo local, tales como la coordinación de acciones secuenciales, lineales, paso a paso. La idea de un tiempo real, desterritorializado y no lineal, que aparece hoy por hoy frecuentemente en la literatura sobre nuevos repertorios tecnológicos, guarda estrechas similitudes con la noción de desanclaje, definida por Giddens como el "despegar las relaciones sociales de sus contextos locales de interacción

3 González enumera como ejemplos de esta integración tecnológica "la electrónica de chip y los circuitos integrados; la condición digital y binaria del procesamiento de información; la condición "telecomunicacional” y la miniaturización de sus componentes. Se trata de tecnologías crecientemente convergentes e integradas (unas interactúan con otras o se integran a las otras, vg., videojuegos en los celulares, cámaras digitales en los celulares, celulares que permiten internet móvil)" (2008: 18). 
y restructurarlas en indefinidos intervalos espacio-temporales" (1999: 32). Así, la noción de tiempo real no sólo refiere a que se trata de un tiempo inmediato y en presente continuo, no definible ya con respecto al espacio y territorio, sino también que el tiempo real encarna la vieja "promesa de "hacer infinito (y ancho) el tiempo finito inmediato" (González y Gómez, 2004: 23). Para González (2008), los nuevos repertorios tecnológicos estarían haciendo posible, para gente del común, lo que el posfordismo se propuso al desagregar las líneas de montaje y descentrar la producción:

En la organización moderna y clásica del trabajo el tiempo era fundamentalmente lineal. Las líneas industriales de montaje indican la naturaleza secuencia (paso a paso, segundo tras segundo) de la producción general humana. Se trataba de reducir el tiempo entre cada secuencia de pasos, como indicador de creciente racionalidad y eficiencia en la producción. Al desagregar y distribuir los momentos de la producción, el posfordismo consiguió incrementar sustancialmente la producción respecto a las formas artesanales y semiindustriales de la producción. La posibilidad de coordinar acciones en tiempo real altera de manera radical la forma de organización de la producción. De esta manera por cada segundo y cada unidad de tiempo presente ocurren, al mismo momento, un rango amplio de operaciones simultáneas que pueden ser coordinadas en red y tiempo real. Esto permite que tareas que requerían mucho tiempo (en tiempo lineal, paso a paso), puedan ejecutarse de manera muy breve en este tiempo reticular. Una película como Toy Story, que en tiempo lineal hubiera requerido en un computador cerca de 90 ańos de trabajo, en tiempo en red, con varios computadores haciendo simultáneamente tareas de animación digital, se tomó poco más de un año (González, 2008: 18).

En otra vía, cuando hacemos referencia a NRT, no estamos hablando, en sentido estricto, de máquinas. Según Mumford (1987) la máquina se caracteriza por una alta complejidad técnica, la dependencia de fuentes de energía externas -como el agua, viento, vapor, energía solar-y su automatismo con respecto a un número limitado de funciones predeterminadas. La herramienta, en cambio, no tiene una función establecida. Ésta depende de la voluntad y el trabajo humano, es decir, "depende de las disposiciones y usos que prevea quien la manipula" (González, 2008: 20). Así, mientras la lavadora es una "máquina”, automatizada y con usos predeterminados, el cuchillo es una herramienta: la lavadora sirve, excepto en situaciones excepcionales, exclusivamente para lavar; pero la función del cuchillo depende en buena medida de si su usuario es una asesina o un cocinero, una bailarina erótica o un ladrón. En los NRT se encuentra, entonces, 
una síntesis novedosa de máquinas y herramientas: automatización de procesos y, al tiempo, adaptación a las necesidades del usuario que será el encargado de "llenarlos" de contenido. De ahí nuestra dificultad para señalar para qué sirve un computador: actúa como máquina pero sirve también para muchas tareas, más o menos predeterminadas, y para otras sin explorar que dependen de la inventiva y necesidades sociales.

Una cuarta cualidad de estos repertorios es que proponen una relación distinta con las pantallas audiovisuales. Gómez y González (2004) sugieren que las primeras pantallas fueron las formas de representación teatral, los teatrinos y las sombras chinescas. El cine constituiría la primera forma automatizada de imagen visual y, posteriormente, visual y sonora. La televisión y el computador implicaron una penetración de las pantallas en escenarios domésticos, mientras el celular insinuó los rasgos de ubicuidad de internet y de convergencia entre red de redes. La clasificación que emplean estos autores sugiere que la primera oleada de pantallas, de la que la del cine es su cristalización más evidente, se caracteriza por la presencia de pantallas hechas para ver de lejos y usar colectivamente. Por otro lado, la televisión, y sus anexos-DVD, videojuegos, teatro casero- están hechos para un consumo de distancia media y de uso en principio grupal. Mientras las pantallas del celular y el computador sugieren una distancia próxima y un uso personal. Se destaca entonces en esta última oleada de pantallas-que comprende a los NRT- la multiplicación y capilarización de su presencia -esto es, parecen cada vez más pequeñas y se encuentran "en todas partes"-, el uso cada vez más personal y el tipo de inmersión o proximidad a la que invitan. Esta inmersión supone también que es necesario tener algunos conocimientos mínimos sobre cómo operan para poder usarlas, cosa que no sucede con el cine y ocurre muy limitadamente con el televisor.

Estas oleadas, según los autores, proponen también formas disímiles de relación con las pantallas. Así, mientras la televisión o el cine plantean una relación de consumo - de desciframiento de textos audiovisuales, por ejemploy los videojuegos, y ciertas funciones del computador, invitan a la ejecución de tareas predeterminadas, la tercera oleada de pantallas se dispone como un espacio: el lugar de realización de obras. Podríamos clasificar en esta categoría a los softwares de diseńo, incluso en sus versiones menos sofisticadas, como los de diseño de diapositivas. Estos softwares proponen al usuario consumo y ejecución de tareas, pero sólo en virtud de la realización de una obra, nunca enteramente predeterminada. Por supuesto, sin duda es arbitraria la distinción entre tecnologías de consumo y tecnologías de la realización de obras. Habrá usuarios que usarán su computador sólo para ver videos musicales y lo cierto es 
que en muchas ocasiones vemos televisión anticipándonos a la imagen -lo que implica un cierto trabajo de producción y no sólo de consumo. Sostenemos, sin embargo, que las posibilidades que ofrecen los NRT para la producción de obras son mucho más extendidas que las que nos ofrecen el cine o la televisión.

En este sentido, cuando hablamos de NRT estamos hablando de algo más que de aparatos o TIC. Estamos hablando de "espacios" y "ambientes", como señalaremos más adelante. De ahí que resulte tan insuficiente la idea de apropiación y uso, frecuente en los estudios sobre tecnología, para dar cuenta de acciones políticas que en y a través de ésta se desarrollan. La noción de apropiación y uso da cuenta de la dimensión más maquinizada del artefacto: los individuos apropiarían la máquina, que les es “ajena” y "externa”, y la harían propia a través de la adaptación y el uso diferenciado según sus necesidades. Fue ésta una perspectiva muy común para los estudios de la comunicación en los ochenta y muy sugerente en la medida en que permitió identificar que existían usos diferenciados de las tecnologías y que éstos dependían más de las mediaciones sociales que del poder -en ocasiones presentado como perverso- de los medios de comunicación. Sin embargo, describir la relación entre nuevos repertorios tecnológicos y acción política en clave de apropiación, sólo nos permite comprender la dimensión más instrumental de los artefactos. Su condición de Tecnologías que sirven de soporte y dispositivo para la comunicación e información humana.

Cualquiera que haya navegado comprende que la web no es en sentido estricto un artefacto: es, sobre todo, un espacio. Hemos señalado ya, entre otras cosas, que los NRT favorecen la coordinación de acciones en tiempo real, actúan como máquinas-herramientas y se constituyen en escenarios para la realización de obras. En otro sentido, hemos afirmado que proponen una suerte de inmersión. El habla común refuerza esta idea: "entramos" a Internet, "estamos" en el computador, "nos salimos" de la WEB. Entrar, estar, salir, son verbos que se refieren más al espacio que al uso instrumental, o que nos indican que más que ante "instrumentos" estamos ante "escenarios": ante ambientes en los que "suceden" cosas y no sólo "con" los que hacemos cosas.

El caso del Tejido de Comunicación y Relaciones Externas para la Verdad y la Vida de la ACIN -Asociación de Cabildos Indígenas del Norte del Cauca- ${ }^{4}$ puede ilustrar el modo en que los NRT se convierten tanto en ambientes como en dispositivos que comunican al mundo online con la experiencia offline. La Asociación de Cabildos Indígenas del Norte de Cauca -ACIN- se encuentra

4 Estos datos corresponden a los resultados obtenidos por el proyecto de "Cultura Política, Ciudad y Ciberciudadanías", en el que participé como investigadora principal, financiado por Colciencias y ejecutado por la Universidad del Valle y la Universidad Pedagógica Nacional durante el año 2008. El informe final de investigación de este proyecto se encuentra en proceso de publicación (Almendra, Vilma, et al., 2010). 
adscrita al Consejo Regional Indígena del Cauca-CRIC-, organismo aglutinador y orientador de las políticas que rigen a las comunidades indígenas del Cauca. Esta organización, 5 nace en 1971 en el resguardo de Tacueyó, Toribío -Cauca. Su objetivo se centra en la reivindicación de los derechos indígenas y su plataforma política se encuentra consignada en el Plan de Vida. Éste no consiste, como en el caso de otros movimientos sociales, en un conjunto de principios escritos que rigen las acciones de la Organización. Por el contrario, el "Plan de Vida" no está plasmado en ningún documento y constituye más una síntesis de la historia de la resistencia indígena, que actúa sobre el presente a través de la palabra dicha, actualizando y revitalizando la urgencia de defender el territorio y la cultura.

El CRIC constituye una organización sólida tanto por su visibilidad como por el número de indígenas que agrupa: se presume que en el departamento hay 190.069 personas indígenas, pertenecientes a ocho grupos étnicos reconocidos (CRIC, 2010). La ACIN es probablemente la asociación indígena más importante del CRIC. Su estructura organizativa disiente de las estructuras ejecutivas usuales -conformadas por presidentes, vicepresidentes, secretarios, etc. $-\mathrm{y}$ retoma, a partir del congreso de Jambaló, en diciembre de 2002, que convocó más de 20.000 personas, las jerarquías tradicionales a través de la figura de los consejeros que, a su vez, deben rendir cuenta a los gobernadores de los cabildos.

En clave de acción colectiva, la ACIN constituye, para Guzmán (2010) el movimiento social más organizado de la región, con mayor poder de convocatoria y, pese a algunos conflictos internos, el más unificado. Es tal vez el mejor ejemplo, en el caso colombiano, del modo en que, con marcos institucionales que los respalden, los movimientos sociales y la participación de la sociedad civil se fortalecen. Estos marcos institucionales fueron otorgados tras la Constitución del 91, que declara a la sociedad colombiana como diversa y heterogénea, y que brinda medidas de protección sin precedentes en América Latina -nótese

5 El CRIC está constituido por nueve Zonas que agrupan a los diferentes Resguardos y Cabildos Indígenas del departamento del Cauca: Zona Centro, Zona Norte, Zona Nororiente, Zona Tierradentro, Zona Occidente, Zona Sur, Zona Pacífico y Zona Bota Caucana. La ACIN agrupa a 14 resguardos y 19 cabildos indígenas de la zona norte. Surgió en 1994, tiene sede en la localidad de Santander de Quilichao (Cauca) y es coordinada por un equipo de representantes de los proyectos comunitarios de la zona que operan como Consejeros, encargados de direccionar políticamente a la Organización. Los tejidos son a la vez metáforas e instancias organizativas, que cuentan con un coordinador o coordinadora y un equipo de trabajo. Según Gómez, et al., (2009) ACIN está integrada por los siguientes cinco Tejidos: 1) Tejido Pueblo y Cultura: encargado de desarrollar programas de salud, educación y dedicado principalmente al trabajo con las mujeres y los jóvenes. 2) Tejido de Defensa de la vida: este tejido involucra todas las acciones y procesos relacionados con la Guardia Indígena y con el programa de Derechos Humanos. 3) Tejido de Justicia y Armonía: aborda el desarrollo del Programa Jurídico y de la Escuela de Derecho Propio. 4) Tejido Económico Ambiental: este tejido incluye programas de soberanía alimentaria, comercialización de alimentos, explotación de minas, protección agroforestal y piscicultura. 5) Tejido de Comunicación y Relaciones Externas para la Verdad y la Vida: éste es el tejido que coordina lo relacionado con las relaciones externas y con los proyectos de comunicación. (Gómez, et al., 2009). 
cómo en Perú y México, por ejemplo, la organización indígena, encubierta en el movimiento campesino, no ha sido objeto de prebendas comparables a las colombianas- a los territorios y formas de gobierno indígenas. Tras la nueva Constitución, el movimiento se visibiliza con un impacto nacional, que no es conquistado por las comunidades negras, y un grado de unidad que no se asimila a ninguna otra forma de acción colectiva en el país.

La ACIN, según Guzmán (2010) suele apelar a formas tradicionales de acción, como la Minga, la Asamblea, la toma de tierras, las manifestaciones y las marchas. En éstas, a pesar de que se han presentado acciones de fuerza y violencia, prevalece el uso de recursos propios como los palos, piedras, caucheras y el caspi.6 Así mismo, como desarrollaremos más adelante, se ha incursionado en el empleo de formas novedosas de acción política, a través de tecnologías con las que han conquistado, exitosamente, apoyo nacional e internacional. Con respecto a sus motivos de lucha, Guzmán (2010) señala como los más significativos: la reivindicación de tierras, los Derechos Humanos y el Derecho Internacional Humanitario, aunque también se abordan asuntos más amplios que tienen que ver con la política económica y social del Estado, la reforma agraria, la administración de la justicia, el rechazo al TLC y la búsqueda de salidas pacíficas al conflicto armado. Para Guzmán (2010) éste es el movimiento que presenta acciones de mayor impacto nacional -dado el número de gente que participa de éstas, como su vigor y visibilidad, por ejemplo las marchas hacia Bogotá. En este sentido se trata también del movimiento que más parece haber sufrido medidas coercitivas, aniquilamientos, hostigamientos y enfrentamientos violentos con el Estado. Al tiempo que se le ha acusado, desde instancias gubernamentales, de sostener relación con grupos subversivos. Ante esto el movimiento ha ratificado su carácter pacífico, ha hecho esfuerzos por distinguirse de la guerrilla y ha propuesto diversos espacios de discusión con el gobierno nacional que, desde lo que nos refiere Guzmán (2010), no siempre se han materializado ni han resultado efectivos como procesos de negociación.

Hasta hace menos de seis años el equipo de comunicaciones de la ACIN contaba sólo con una máquina de escribir manual en la que se transcribían las actas de las reuniones y un conjunto de radioteléfonos que apenas alcanzaban para ponerse en contacto entre Cabildos. Hoy, no sólo el trabajo en comunicación se ha diversificado y politizado, sino que también se ha caracterizado por acudir a una combinatoria de medios, que el colectivo distingue entre medios apropiados -foráneos: como las radios comunitarias indígenas, Radio Pa'yumat, Radio Nasa, Voces de Nuestra Tierra; equipo de impresos, equipo de Video y equipo

6 Corteza de árbol que, mezclada con el agua produce picazón y alergia. 
encargado del manejo de la página web de la asociación- y con un conjunto de medios propios -ancestrales, como: las mingas, los rituales y las asambleas. $\mathrm{Su}$ impacto le ha valido diversos reconocimientos nacionales e internacionales y en el 2008 la desaparecida Revista Cambio, premió el Tejido de Comunicaciones de la ACIN como uno de los 25 líderes colombianos destacados por su trabajo en procesos de comunicación con sectores sociales y populares del país:

\begin{abstract}
[...] la información de este tejido de comunicaciones ya llega a América Latina, Europa y Estados Unidos a través de una red de afiliados virtuales que supera los 20.000. Una revolución informativa que está demostrando que las comunidades indígenas no están solas y que son, como dice uno de sus documentales premiados en festivales internacionales, unos alzados [...] en bastones de mando. (Revista Cambio, 2008).
\end{abstract}

El crecimiento del sector de comunicaciones de la ACIN fue impulsado en buena medida por la llegada del Telecentro en el 2001. La figura de telecentros fue promovida en la región por el CIAT y la Universidad Autónoma de Occidente. En principio se le concebía como un recurso para la comercialización de productos comunitarios, que operaba a través de la donación de algunos computadores y la capacitación a líderes para su uso. ACIN fue una de las organizaciones seleccionadas para ser pionera en la instalación de telecentros que, se aspiraba, fuesen de acceso público para las personas del municipio. Sin embargo, a medida que el Telecentro derivó más en un proyecto político, y las amenazas contra la ACIN se recrudecieron, se hizo necesario restringir el acceso a los computadores.

Con el Telecentro llegaron a ACIN dos computadores, un escáner, dos cámaras web y la conexión a la red por línea telefónica. Así mismo, se adelantaron capacitaciones en el manejo de programas y se abrieron correos electrónicos para algunos líderes de la ACIN, que eran revisados y contestados, previas instrucciones, por Vilma Almendra, joven indígena seleccionada por la Organización para encargarse de comunicaciones. Los primeros seis meses del Telecentro parecen resultar improductivos, y durante cerca de un año y medio Vilma desarrolló un trabajo rutinario, sin muchos sobresaltos. La Universidad Autónoma, por su parte, insistía en la necesidad de socializar el proyecto de telecentros con la comunidad, por lo que la Organización decidió abrir un espacio en la Asamblea del 2001 para ofrecer un informe sobre el proceso. Las asambleas se realizan cada tres meses, en éstas cada uno de los cabildos y de los siete procesos presenta sus informes, lo que convierte a las asambleas en importantes eventos de discusión 
y encuentro público. Para Vilma esta presentación constituía todo un desafío. A la asamblea asistieron 500 personas y, por su experiencia en otras asambleas, Vilma Almendra sabía que no se trataba de un público fácil. Previendo la presentación había realizado algunas carteleras, porque no contaban con videobeam. Así, soportada únicamente por sus carteleras, se enfrentó a la asamblea con más dudas que respuestas. En media hora terminó su exposición. Al terminar de hablar le preguntó a la gente si había entendido. Todos le dijeron que no. Era de esperarse. Cristóbal Secué, consejero promotor del Telecentro en la ACIN, la tranquilizó con una frase brutal: "La gente ni maneja el computador. Qué van a entender si nosotros apenas estamos entendiendo" (Almendra, et al., 2010 : 45).

El giro político que toma el Telecentro se produce en el 2002, con la incursión guerrillera a Toribío, que duró cerca de 20 horas. Durante este periodo las líneas telefónicas fueron cortadas y se descargaron los radioteléfonos. La población quedó a merced de la guerrilla y sin medios de comunicación con el exterior. Sin embargo, en Tacueyó, vereda cercana a Toribío, había Internet satelital gracias al servicio de Compartel, lo que permitió que Ezequiel Bitonás, líder indígena, pudiera establecer comunicación con Santander. Curiosamente, Bitonás había sido de los más francos opositores al proyecto de Telecentro. Pero, ante la amenaza de la toma, logró comunicarse con Vilma que se encontraba conectada a Internet, por línea telefónica, desde Santander de Quilichao. Por entonces la Organización contaba con pocos contactos de Internet. Uno de esos contactos era Manuel Rozental, médico y simpatizante de la causa indígena, en Canadá. Fue precisamente Rozental el contacto clave para la visibilización del hecho y la movilización internacional que sucedió a la toma de Toribío. El asunto funcionó de la siguiente manera: Bitonás narraba por teléfono lo que iba pasando y Vilma Almendra, que por aquella época "no sabía redactar", transcribía los mensajes a Manuel Rozental en Canadá. La divulgación internacional del hecho fue clave para la protección de la población durante la toma y, además, posibilitó un intercambio de visitas entre miembros de la ACIN, que viajaron a Canadá, y cerca de 30 personas pertenecientes a diversas organizaciones canadienses -sindicatos, iglesias y también líderes de movimientos sociales- que viajaron a Colombia.

Esta situación supuso para la organización indígena la apertura de un contacto internacional directo, dotó políticamente el uso de tecnologías en la ACIN y posibilitó el apoyo de la Organización al naciente Tejido de Comunicaciones. La página web nació en el contexto de este proceso. En un viaje internacional a Ezequiel Vitonás, líder indígena, se le preguntó insistentemente si la ACIN tenía página web. Inquieto por la pregunta, Vitonás propuso que se diseñara la página con apoyo de la Universidad Autónoma, como en efecto se hizo en el 
2003. Hacia esa fecha, la ACIN decide desvincularse de la tutela del CIAT y la Universidad, y asume financiar el Tejido a través de un porcentaje que todos los proyectos de la Organización deben aportar.

Desde entonces, la web ha implicado para la ACIN no sólo un nuevo escenario, al que se extienden formas heredadas de su acción política, sino también la reconfiguración, dada la relación emergente entre movimiento y tecnologías, de lo que hasta el momento se concebía como un movimiento de fuerte adhesión territorial y local. En su ejercicio político las tecnologías informáticas actúan no sólo como máquinas que reciclan y potencian las funciones de otras, sino también como lugares "en" los que ocurren acciones, en los que se materializan y concretan vínculos y en los que se despliega una suerte de creatividad política en la gestión de redes y alianzas. Acerca de esta imaginación conexionista, de la que hablan Boltanski y Chiapello: "no merece la pena insistir, ya que resulta evidente, en la manera en que el considerable desarrollo de los dispositivos técnicos de comunicación y trasporte ha podido estimular la imaginación conexionista" (Boltanski, et al. 2002: 208). ${ }^{7}$

Para el caso del Tejido de Comunicación y Relaciones Externas para la Verdad y la Vida, el evento de Toribío y la apertura de la página web, representó abrir una ventana al mundo: Vilma Almendra lo describe como un "a salir y que salga y se salga" (Almendra, et al., 2010: 47). Un salir corporal y físico, representado por viajes y visitas internacionales, y un salir cibernauta, una primera relación con la Internet como ambiente que permite navegar, moverse, crear rutas y caminos para "salir", para "fugarse", pero también para encontrarse con otros. La web permitió a la Organización establecer nuevos contactos -en parte gracias a la gestión Manuel Rozental que "donó" los suyos- y conectarse, a su vez, con pueblos indígenas nacionales e internacionales. De este proceso emergieron

7 Sin embargo, retomando a Boltanski y Chiapello (2002), nos permitimos discutir un poco esta suerte de determinismo tecnológico que suele señalar con euforia a las tecnologías como los dispositivos centrales de las transformaciones en los modos de coordinación de acciones políticas. Estos investigadores permiten comprender, en primer lugar, que las formaciones en red no son un asunto exclusivo de ambientes tecnológicos y que, de hecho, como ilustran reiteradamente, éstas se gestionan en ámbitos diversos (empresariales, comunitarios) a través de acciones offline y en tiempo lineal. En segundo lugar, Boltanski y Chiapello enfatizan en el hecho que los modos de organización en red deben su eficacia tanto a la grandeza (entendida como capacidad para generar redes y vínculos) de los individuos y los movimientos, como a la disposición de las redes para "modificarse sin descanso" (Boltanski y Chiapello, 2002: 160), esto es, para probar su plasticidad. Así pues, lo que Boltanski y Chiapello nos sugieren es que para comprender aquello que estos movimientos sociales hacen en la web no basta con atender el trabajo de gestión de vínculos online, sino también la cualidad y calidad de las alianzas que se establecen y el trabajo humano, no mediado tecnológicamente, gris y rutinario que hace de los movimientos sociales más o menos conexionistas. 
cambios significativos para el movimiento. Los aliados se multiplicaron, pero también se resignificaron los adversarios: de los aliados locales a los aliados de todo el mundo, de los que amenazan el territorio a las políticas globales que amenazan a los sectores populares. La organización indígena del norte del Cauca se internacionalizó y, al mismo tiempo, Vilma Almendra, como operadora directa de este proceso, vivió paulatinamente una experiencia de mayor encuentro con su identidad indígena y su territorio. La relación con el afuera permitió, a su vez, una mayor integración de Vilma Almendra con el adentro. Visitar otros lugares, recibir visitas, contestar correos, establecer contactos, fueron trabajos que no sólo desarrollaron la capacidad de gestión de la organización indígena, sino que también le permitieron a Vilma Almendra reconocer como valioso el trabajo realizado por su comunidad: "y a uno acá le parece tan normal, es lo que yo hago todos los días, pero allá les parece importante [...]”, asegura Vilma. (Almendra, et al, 2010).

\section{Subpolítica o política menor: ¡̨la emergencia de una política por proyectos? ${ }^{8}$}

Las posibilidades que ofrecen los avances tecnológicos no están inherentemente en los artefactos individuales, sino que son contingentes con respecto a las redes en las que están localizadas [...] Una politica de la tecnología que promueva la emancipación requiere algo más que hardware y software, requiere wetware-cuerpos, fuidos y agencia bumana.

Judy Wajcman, 2006

La mayor parte de los autores revisados relaciona la acción política en la web con formas de subpolítica (Beck, 2001) o de política menor (Lazzarato, 2006). La idea de política menor se plantea en oposición a la existencia de una política mayor. ${ }^{9}$ Esta última, se asegura, se habría erigido sobre paradigmas que reducen los movimientos sociales a la lucha de clases y a la realización de un solo proyecto, cuyo objetivo principal es la toma del poder. La subpolítica, en cambio, alude a formas de lo político que "irrumpen y brotan más allá de las responsabilidades formales y las jerarquías” (Beck, 2001: 135), esto es, políticas que se gestan al

8 Este título pretende establecer un juego de palabras con "La Formación de la Ciudad por Proyectos", título del capítulo II del libro El Nuevo Espíritu del Capitalismo (Boltanski y Chiapello, 2002: 153), documento en el que se ha basado algunas de las reflexiones centrales contenidas en este texto.

9 Para el caso de Lazzarato (2006) las nociones de política mayor y política menor constituirían una suerte de tipo ideal que, por supuesto, no es del todo fiel a los modos en que opera la política en el mundo empírico -en el que con frecuencia conviven y se mezclan formas mayores y menores- pero que resulta útil para "resaltar los rasgos más predominantes y homogenizantes de las formas políticas emergentes y heredadas" (Lazzarato, 2006: 35). 
margen de las instituciones del sistema político tradicional, representado por el Estado-nación. La subpolítica denota entonces la capacidad de auto-organización de la sociedad civil, a través de formas de política directa, es decir, no mediadas por instituciones representativas, como los partidos, y agenciadas más como iniciativas ciudadanas que "han tomado el poder temáticamente" (Beck, 2001: 36). En este sentido, a diferencia de la mayor, se trata de una política de la multiplicidad de objetivos y formas de lucha que no buscan tanto la toma del poder como la ampliación del mismo.

En esta medida, Lazzarato y Beck coinciden en afirmar que en las formas de subpolítica cobran relevancia las estrategias simbólicas y expresivas, que describen un horizonte amplio de posibilidades al que pueden sumarse muchos: recuérdese el importante papel que jugó la consigna "Otro mundo es posible" en el caso de las protestas de Seattle, en 1999, contra la Cumbre de la Organización Mundial del Comercio. De manera sintética, puede decirse que estos autores aluden a estos movimientos en clave de cinco puntos en común: a) son movimientos que se fundan en la difusión de proyectos y códigos culturales diversos; b) una de sus preocupaciones más sentida es la visibilización de conflictos sociales y la denuncia a través del discurso; c) se coordinan a través de estructuras reticulares y flexibles; d) acuden a acciones simbólicas y actos performativos; y e) se fundan en una profunda politización de lo social, lo cultural y la vida cotidiana.

Para Castells (1999), estos movimientos en contextos globales pueden comprenderse a partir de tres aspectos: el modo en que definen a su adversario, las formas en que el movimiento se opone a éste y el uso que hacen de los nuevos repertorios tecnológicos. Al respecto, sostiene que el adversario común es lo que se ha denominado nuevo orden político y económico a nivel global que genera desigualdades y exclusiones. Es este adversario, de cierta forma "simbólico", el que favorece la integración de tantos sectores y movimientos -feministas, ambientalistas, movimientos LGTBI e indígenas, por ejemplo- en acciones coyunturales.

En el caso de la experiencia de ACIN, podemos señalar que en la actualidad el movimiento indígena está construyendo una forma de gestión política que combina principios y formas de lucha provenientes tanto de viejos como nuevos paradigmas. Vemos cómo el movimiento indígena, si bien se origina en luchas ancestrales por la recuperación de tierras, migra hoy hacia búsquedas de más largo aliento que involucran aspectos que trascienden las reivindicaciones étnicas. Las luchas fundantes del movimiento indígena pueden ubicarse en la lógica de la política mayor, según la cual el pueblo indígena, como Sujeto de la Historia, enfrenta unos enemigos de clase claramente definidos -los terratenientes y el gobierno regional y nacional, por ejemplo- y a estrategias encaminadas a la re- 
cuperación de las tierras: invasión de terrenos, apelación a Títulos de Propiedad de tiempos de la Colonia, solicitudes y demandas por la asignación de terrenos y recursos, etc. Sin embargo, también en el movimiento se aprecia la emergencia de una política menor. Un ejemplo de eso es el paso del mandato de "la toma de tierras", como consigna y bandera política, al de "la liberación de la madre tierra", ${ }^{10}$ como principio articulador de la lucha que hoy libra el movimiento. La idea de "libertad para la madre tierra" expresa un panorama extenso que convoca las búsquedas no sólo de los indígenas sino de amplios sectores de la población nacional e internacional. El Sujeto Histórico ya no es sólo el pueblo indígena. El abanico se abre a nuevos y variados ámbitos geográficos y a sectores sociales diversos: campesinos, desplazados, corteros de caña, afrocolombianos, organizaciones populares nacionales e internacionales, mujeres, estudiantes, medioambientalistas, otros pueblos indígenas de dentro y fuera del país. Igualmente, el derrotero de las luchas deja de ser único y homogéneo y se abre a muchas bifurcaciones posibles y no previsibles desde el comienzo: "construir la tierra liberada", aunque es una exhortación a la acción, no apela a una solución puntual y predefinida. Se trata de un principio que, como señala Lazzarato (2003), convoca la participación de diversos actores sociales e invita a "actualizaciones" constantes desde las que se pueden construir soluciones siempre provisionales y formas de acción diversas (Almendra, et al., 2010).

En este sentido, la "Minga Nacional de Resistencia Indígena y Popular" (octubre - noviembre de 2008) y la agenda de discusión que el movimiento le propuso al gobierno de Álvaro Uribe, ${ }^{11}$ también dan cuenta del proceso de transformación que se está generando desde el interior del movimiento indígena. Nótese cómo en esta agenda, a la par que se plantean asuntos propios del movimiento indígena, se reclama la discusión sobre temáticas de orden global, como el Tratado de Libre Comercio (TLC) y la lucha contra la pobreza y la violencia, que ya han sido considerados por el movimiento en algunas de las movilizaciones más importantes realizadas en los últimos años como "La marcha indígena y popular" de 2004 o la "Consulta popular contra el TLC" en 2005.

10 El Mandato propone que "luchar por la tierra no es un problema ni un deber solamente de los indígenas, sino un mandato ancestral de todos los pueblos, de todos los hombres y mujeres que defienden la vida. Porque solo en la lucha para poner en libertad a nuestra madre recuperamos la dignidad, alcanzamos la justicia y la equidad, y caminamos la palabra que defiende la vida. Seguiremos coordinando, haciendo las alianzas estratégicas y llamando desde las palabras convertidas en acción en el espíritu de la comunidad a despertar las conciencias y a recuperar la Madre Tierra para ser libres" (CRIC, 2010).

11 La Minga Nacional de Resistencia Indígena y Popular propone los siguientes puntos de discusión: a) rechazar todos los Tratados de Libre Comercio; b) exigir la derogatoria de las reformas constitucionales y las legislación de despojo y exclusión de los más pobres; c) rechazar todas las formas de terror y violencia armada; d) exigir el cumplimiento de las normas, acuerdos y convenio establecidos e ignorados sistemáticamente; e) construir la Agenda de los Pueblos (ACIN, 2008). 
Esta pluralidad de actores, demandas políticas y formas de lucha transforma la concepción estática y homogénea de la identidad indígena, tal y como según Castells (1999) le ocurre a la sociedad civil en la modernidad. Para este autor, hoy por hoy se observan tres formas diferentes de identidad colectiva: a) Identidad legitimadora: se trata de identidades moldeadas por las instituciones dominantes con el fin de extender y racionalizar su control social a través de formas instrumentales de participación de la sociedad civil; b) Identidad de resistencia: refiere a actores que se encuentran en posiciones devaluadas o estigmatizadas y construyen trincheras de resistencia y supervivencia basándose en principios opuestos a los que impregnan la sociedad dominante; c) Identidad proyecto: alude a actores sociales con capacidad no sólo de resistir sino también de proponer transformaciones sociales estructurales y redefiniciones de su identidad que trascienden las imposiciones del programa institucional dominante.

En el caso de ACIN encontramos la consolidación de un movimiento social basado no solamente en una identidad de resistencia sino, también, en la construcción de una identidad proyecto. En términos de cultura política, ACIN es una experiencia social pensada "glocalmente" (Escobar, 2005), en la que lo local sigue siendo importante pero no se convierte en condición fundamental para instituir y organizar la noción de "comunidad" o de "proyecto colectivo". La identidad étnica mantiene su centralidad pero se buscan alianzas con otros grupos y organizaciones con los que se comparten luchas y resistencias frente al nuevo orden global.

Así, como señalábamos antes, en ACIN emergen ciertas prácticas políticas que no podrían aparecer sin la presencia de los nuevos repertorios tecnológicos pero que tampoco podrían explicarse sólo por su existencia, como nos lo sugerirían los determinismos tecnológicos. En ACIN, la presencia de las tecnologías no puede leerse como un gesto mecánico de adición de un artefacto tecnológico a un movimiento social: los nuevos repertorios tecnológicos le han permitido a ACIN vincularse y visibilizarse globalmente. Pero también la Organización ha hecho suyas, ha moldeado, las tecnologías de una manera muy particular. Un ejemplo es la "chiva-net", como modalidad de integración tecnológica que combinaba transporte terrestre (la chiva), la Internet y la radio comunitaria. La "chiva-net" fue creada como recurso para alimentar las trasmisiones de la emisora comunitaria de Toribío y consistía en el siguiente proceso: una persona del Tejido de Comunicación de la ACIN, en Santader de Quilichao, seleccionaba en Internet algunas noticias internacionales y las copiaba en un disket (o CD); el disket se enviaba por chiva hasta la localidad de Toribío (a dos horas de Santander de Quilichao); allí otra persona recibía el disket, lo abría y transmitía las 
noticias internacionales a través de la radio comunitaria. Esta estrategia se utilizó aproximadamente hasta el 2004, año en el que se instaló Internet en Toribío.

Por otro lado, el principio de coordinación de acciones en tiempo real, que posibilitan los nuevos repertorios tecnológicos, ha sido decisivo para el diseño y ejecución de las últimas movilizaciones que ha realizado el movimiento indígena nortecaucano: la "Visita a Bogotá. Por el País que Queremos" (julio de 2007) y la "Marcha Nacional de Resistencia Popular e Indígena" (octubre de 2008). Estas movilizaciones, que recorrieron el país de sur a centro, implicaron una logística enorme coordinada en gran parte vía Internet y contaron con transmisiones en directo para las radios comunitarias -que se podían escuchar a través de la red por real-audio- y con una grupo de corresponsales indígenas que difundían permanentemente comunicados a través de la Internet, los cuales eran traducidos casi inmediatamente al inglés, al alemán, al portugués y al italiano, gracias a la red de solidaridades internacionales que ACIN ha ido construyendo.

$\mathrm{Al}$ respecto, Tamayo (2007) asegura que los movimientos sociales han ido, paulatinamente, sumándose al proceso de colonización de Internet a pesar de que algunos han tenido que lidiar con las restricciones de infraestructura, del analfabetismo tecnológico de las comunidades, así como con el desafío de optimizar y dar sentido a su uso. En este sentido se resaltan los casos del movimiento mexicano Zapatista (EZLN), el Movimiento de los Sin Tierra (Brasil), la Coordinadora Latinoamericana de Organizaciones del Campo (CLOC), la red internacional "Vía Campesina", la Acción Global de los Pueblos (AGP), la Asociación por una Tasa a las Transacciones financieras especulativas para Ayuda a los Ciudadanos/as (ATTAC), la Marcha Mundial de las Mujeres, la Campaña Continental contra el ALCA y, por supuesto, la "batalla de Seattle" -30 de noviembre de 1999-, como el comienzo simbólico de sucesivas movilizaciones de carácter global.

En todos los casos mencionados, provengan o no de movimientos más o menos tradicionales, las protestas y acciones políticas más sonoras han sido organizadas en red, en tiempo real y agenciadas por individuos y movimientos conectados de manera contingente. En su libro Multitudes Inteligentes (2002), Howard Rheingold reconoce como multitudes inteligentes a: "grupos de personas que emprenden movilizaciones colectivas -políticas, sociales, económicas-gracias a que un nuevo medio de comunicación posibilita otros modos de organización, a una escala novedosa, entre personas que hasta entonces no podían coordinar tales movimientos" (Rheingold, 2002: 25). A lo que alude Rheingold es entonces a acontecimientos que se originan tras la asociación voluntaria y, repetimos, más o menos espontánea, de individuos y movimientos cuya alianza sería impensable 
si la red que los teje no se hubiera pactado en y por medio de nuevos repertorios tecnológicos. Estas estrategias y acciones afectan las formas de organización de los movimientos sociales. Así, si en la política mayor prevalecen las estructuras jerarquizadas, más o menos burocráticas, en las que el partido político constituye el eje de una organización que se ramifica hacia otras instancias y movimientos sociales (sindicatos, comunidades y grupos) y se construye así una política sectorial. ${ }^{12}$ En la política menor, en cambio, se opera a través de la cooperación solidaria de sus miembros, sin que exista una cabeza que centralice y defina los rumbos de la organización. Se trata pues de una arquitectura en red: "redes que convocan nudos diversos de intereses en alianzas contingentes y concretas" (Lazzarato, 2006: 36). Esta tecnología, junto con otras dinámicas comunicacionales, les permite una forma de gestión policéntrica y una comunicación fluida a nivel interno, por lo que uno de sus mayores usos es el del envío de mensajes por correo electrónico.

La red sería entonces - nótese: tanto en el movimiento antiglobalización como en las protestas contra Aznar- el modo de organización a través del cual se despliegan estas formas de acción política. En este sentido, si nos refiriéramos al caso de la subpolítica o política menor, tendríamos que decir que no son los vínculos entre movimientos e individuos los que resultan determinantes para comprender las formas de organización política emergente, sino los proyectos, esto es los acontecimientos (Lazzarato, 2006), para los cuales estos individuos y movimientos constituyen redes móviles y transitorias.

Lazzarato nombra como acontecimientos a estas acciones vigorosas y expresivas que en la subpolítica aparecen como tácticas que movilizan y visibilizan procesos sociales (2006). No se trata entonces de estrategias racionales, que actúan como medio para el cumplimiento de un plan predeterminado, sino más bien de manifestaciones en ocasiones espontáneas que constituyen un fin en sí mismo, en tanto su objetivo es la expresión -de repudio, por ejemplo en el caso del 13 de marzo español. Es comprensible, entonces, el importante papel que cumple la acción simbólica en el contexto de la política menor: el acto de nombrar es, en sí mismo, un acto político. La página de la ACIN nos revela la efectividad expresiva del movimiento: sobre la defensa de la lengua los indígenas dicen "la historia quedó incrustada en el paladar" (www.nasaacin.org, consultada en noviembre de 2010), en rechazo al sistema económico dirán "tenemos para ser" -en oposición al "somos para tener" que a su juicio propone el capitalismo- (www.nasaacin.org, consultada en noviembre de 2010), y para hablar de su lucha dirán "venimos

12 Esto es, lo que el partido tiene que decir a los sindicatos, a las mujeres, a las comunidades étnicas, a las comunidades locales, etc. 
caminando desde la historia" (www.nasaacin.org, consultada en diciembre de 2010) en una clara alusión al pasado que, puesto en ámbitos globales, adquiere nuevos significados y se reactualiza.

El acontecimiento, como proyecto en la política menor, sería el eje sobre el que se concentraría el trabajo de "coordinar recursos diversos con un objetivo preciso y por un periodo limitado en el tiempo" (Boltanski y Chiapello, 2002: 157). La Minga Indígena de 2008 en Colombia, de la que hablamos previamente, cuyo objetivo central era la exposición de una agenda de discusión con el Gobierno Central, constituye un buen ejemplo de ello. La Minga requirió una logística que permitiera el desplazamiento y hospedaje de más de 30.000 personas en la Universidad del Valle, así como la difusión permanente de información producida por la ACIN en medios internacionales y nacionales. Para ello el Tejido de Comunicaciones de la ACIN13 estableció contactos no sólo con movimientos indígenas y sociales de Colombia sino con otros movimientos de orden global que, como Focus on the Global South, 14 acompanaron la marcha hasta su arribo a la ciudad de Cali. Se trató, entonces, de una auténtica cooperación entre cerebros (Lazzarato, 2006), una "multiplicación de encuentros y deconexiones temporales, pero reactivables con grupos diversos, realizadas eventualmente a distancias sociales, profesionales, geográficas y culturales muy elevadas" (Boltanski y Chiapello, 2002: 155). Esta plasticidad del trabajo de los nuevos movimientos sociales, su intención de procurarse redes constantemente, afecta, como veremos en el siguiente aparte, las formas de trabajo que en ella se realizan y el estatuto de sus militantes.

\section{Consideraciones finales: el caso de Vilma Almendra}

Vilma Almendra ${ }^{15}$ es una indígena nasa de 30 años que se desempeñaba, hasta hace poco, como Directora del Tejido de Comunicaciones de la ACIN. Estudió comunicación social en la Universidad Autónoma, gracias a una beca concedida por la Universidad, y hasta hace ocho años su formación política era precaria y apenas si sabía encender un computador. Su trabajo en la ACIN ha

13 Estos datos corresponden a los resultados obtenidos por el proyecto de "Cultura Política, Ciudad y Ciberciudadanías”, financiado por Colciencias y ejecutado por la Universidad del Valle y la Universidad Pedagógica Nacional durante el año 2008, bajo la coordinación general de la profesora Rocío Rueda, en el que participé como asistente de investigación.

14 Movimiento antiglobalización con sede en Tailandia, preocupado por la democratización de la economía global, coordinado por Walden Bello.

15 : Vilma Almendra fue entrevistada en diversas ocasiones por el proyecto de investigación "Cultura Política, Ciudad y Ciberciudadanías”, financiado por Colciencias y ejecutado por la Universidad del Valle y la Universidad Pedagógica Nacional durante el año 2008, en el que participé como asistente de investigación. Los datos que se refieren en este capítulo corresponden a las entrevistas realizadas durante la ejecución del proyecto. 
constituido entonces un proceso largo de aprendizaje político y de alfabetización tecnológica, que se ha trazado en coyunturas y caminos azarosos. Su participación en el movimiento indígena no corresponde estrictamente a lo que reconocemos como empleo, sino más bien a lo que Boltanski y Chiapello denominan como actividad voluntaria, no medible ni remunerada -que, sin embargo, puede ser cooptada por el mercado del trabajo, tal y como sucede con los líderes naturales de sectores populares, frecuentemente contratados por ONG y fundaciones para el acompañamiento de procesos comunitarios.

Así, como asegura Lazaratto (2006) con respecto a la política menor, para el caso de Vilma Almendra no nos encontramos ante una militancia que se produzca exclusivamente respecto a la Organización, ACIN en este caso, sino más bien una militancia que se experimenta como adhesión a una causa -para el caso de Vilma y, como pudimos comprobar para muchos jóvenes indígenas, la causa expresa es la lucha contra la globalización- lo que permite su adhesión a otros movimientos sociales. Su actividad en la ACIN puede entenderse a través de la descripción de varias actividades menores que enlistamos a continuación (Almendra, et al., 2010). Nótese cómo en todas éstas el trabajo que realiza dista mucho de ser rutinario y preestablecido. Por el contrario, se configura y reorganiza en la coyuntura, ante el acontecimiento y se reinventa a partir de los diversos proyectos que emprende el Tejido de Comunicaciones:

- Gestión (online y offline) de contactos relevantes para la organización.

- Creación de obras (generalmente de textos online) que responden a coyunturas inmediatas o de largo plazo de la organización.

- Educación y alfabetización tecnológica de miembros de la organización.

- Edición y gestión de información online y promoción de la instalación de temas en la agenda de la organización.

- Diseño de políticas de información y redes.

- Representación pública de la organización en diversos eventos y procesos nacionales e internacionales.

- Liderazgo en movilización.

Adviértase cómo, la mayor parte de las actividades que efectúa Vilma Almendra están orientadas hacia la generación y mantenimiento de vínculos -incluso en aquellas actividades en las que se aspira a que ésta sea una labor secundaria. Por ejemplo, tras cada viaje en el que Vilma representa a la Organización suele acumular nuevos vínculos y contactos para las listas de correo y la página web. El tipo de trabajo que realiza revela una alta polivalencia: no sólo se desempeña 
como intelectual que planea y gerencia proyectos, sino que también actúa como movilizadora y creadora de obras. Todas estas características coinciden con lo que Boltanski y Chiapello reconocen como individuo conexionista, en este caso en el marco de un proyecto político en el que Vilma actúa como mediadora, en procura ya no sólo de sus intereses privados sino de diversos intereses políticos que le permiten ponerse en relación, a su vez, con proyectos diversos y con múltiples causas.

El caso de Vilma Almendra ilustra un tipo de agencia política cuyo acento está puesto en el ejercicio de insertarse y tejer redes, para lo que Vilma en particular, pero otros individuos como ella en general -como las puenteras, como denomina la Red Pazífica de Mujeres a las encargadas de trazar puentes entre la Red y otros movimientos y personas- despliegan diversas habilidades sociales -capacidades de comunicación, carisma, adaptabilidad, liderazgo-, un agudo sentido de la oportunidad que les permite elegir y anticipar el vínculo y una cierta generosidad con la información que se expresa en sentido del bien público y reconocimiento de la importancia de que la información circule sin restricción (Boltanski y Chiapello, 2002).

Podemos reconocer entonces que la política menor y su lógica del acontecimiento parecen demandar la participación de mediadores, individuos y movimientos conexionistas, capaces de sumarse a proyectos y acciones de corto plazo en los que se requiere una cierta flexibilidad de objetivos. Estos mediadores deben estar así dispuestos a integrarse transitoriamente a escenarios políticos móviles -lo que probablemente resultaría impensable para el individuo político más clásico- esto es, en palabras de Boltanski y Chiapello: "sentirse cómodo en un mundo en red supone permanecer reactivo, móvil, física e intelectualmente" (2002: 167).

En este sentido, la militancia en movimientos sociales de esta naturaleza requiere la combinatoria no sólo de creatividad política y tecnológica, sino también de formas de acción heredadas con nuevos repertorios de acción. En este sentido, para la ACIN son tan relevantes las asambleas multitudinarias y las marchas, como las nutridas listas de correo debidamente administradas por los miembros del Tejido de Comunicaciones, quizás los más jóvenes entre la organización. ${ }^{16}$

Sin embargo, habría que matizar el entusiasmo que despiertan procesos como los del movimiento indígena nortecaucano. En este sentido, Boltanski y Chiapello expresan su inquietud con respecto al compromiso duradero que pueda derivarse de un mundo por proyectos:

16 En sentido estricto los más jóvenes están en la Guardia Indígena y en los miles de niños que participan como ciudadanos en las Asambleas y las Mingas (Almendra, et al., 2010). 
Cada cual sabe en el momento en que se adhiere a un proyecto, que la empresa a la que va a contribuir está destinada a vivir durante un tiempo limitado, que no sólo puede, sino que debe terminarse. El horizonte de un fin inevitable y deseable acompaña por lo tanto, al compromiso sin tener por qué afectar al entusiasmo [...] Tener la posibilidad de no comprometerse con un determinado proyecto y, por lo tanto, disfrutar de la posibilidad de elegir los proyectos en los que uno participa es una condición para el funcionamiento armonioso de la ciudad (2002:165).

Es éste un punto neurálgico para pensar críticamente las formas de política menor o subpolítica. Para Lazzarato (2006), uno de los rasgos predominantes de una política mayor es que ésta se configura en procesos de largo aliento, a través de una trayectoria más o menos lineal de acumulación de saberes que este autor reconoce como experiencia. Por otro lado, la política menor estaría hablando de alianzas transitorias, de individuos que se suman a muchos mundos y causas posibles y de formas de cooperación política itinerantes y fluidas. ¿Pueden estas formas de política, caracterizadas por el compromiso a corto plazo, engendrar estrategias de transformación que superen el acontecimiento? ¿Qué tipo de identidades -colectivas e individuales- se gestan en una política por proyectos, en la que la trayectoria política se arma sobre fragmentos? Alguna pista al respecto insinúan Boltanski y Chiapello (2002: 165) cuando afirman que es la esperanza del proyecto por-venir, del proyecto futuro, el que anima estas formas de entusiasmo de corto plazo. La revisión del caso de la ACIN permite comprender cómo esta organización se ha armado un relato coherente de su identidad política, a pesar de la rapidez con la que se adapta a una lógica por proyectos, gracias a un constante movimiento entre la red global a la que se adhiere y las acciones y objetos locales, offline, de disputa, que remiten al territorio, la etnia y a prácticas jerarquizadas y milenarias de organización.

Los resultados de este proceso son impredecibles y habría que entenderlos como emergentes. Lo emergente, como seńalábamos, indica ese estado en que los términos de la relación se manifiestan como 'algo' sustancialmente distinto de lo que inicialmente eran. Así, la relación entre movimiento indígena y tecnologías constituye un conjunto opaco de "posibilidades", cuya identidad, límites y alcances se cristalizarán o definirán en virtud de su relación. Por lo pronto, observamos que en la ACIN hay una apelación recurrente al pasado como el lugar desde el cual proyectarse hacia el futuro cada vez más complejo, abierto a nuevas alternativas y posibilidades, en las que el movimiento indígena -no sin contradicciones internas, por supuesto- está tratando de conectarse con 
las luchas de otros sectores sociales y está planteándose preguntas y problemas políticos más allá del plano reivindicatorio. El nosotros en el que se apoya hoy no es ya no en un conjunto identitario determinado a priori, en razón de la raza, sino una identidad que se enriquece y transforma a partir de múltiples y variadas formas de encuentro y vínculo social que suceden, cada vez más, en ambientes tecnológicos. Es probablemente esta suma del movimiento indígena a nuevos objetos, iniciativas y mundos posibles -"en los que la clase ya no es el único lugar de disputa", Lazzarato (2006) - la que invita a afianzarse en una política por proyectos en la que los muchos objetivos e iniciativas se enredan temporalmente sin renunciar a su heterogeneidad.

\section{Referencias}

Almendra, V.; Giraldo, D.; Gómez, R.; González, J.; Henao, A.; Ulcué, G. y Unás, V. (2009). Tierra y Silicio: cómo la palabra y la acción política de pueblos indígenas cultivan entornos digitales. Informe final, proyecto Cultura política, ciudad y ciberciudadanías (Colciencias, Universidad del Valle y Universidad Pedagógica Nacional). Documento en proceso de publicación, editorial de la Universidad del Valle.

Beck, U. (2001). La invención de lo Politico, México: Fondo de Cultura Económica.

Boltanski, L.; Chiapello, É. (2002): "II. La Formación de la ciudad por proyectos" El nuevo Espiritu del Capitalismo, Madrid: Ediciones Akal. pp. 153-237.

Castells, M. (1986). La ciudady las masas. Sociología de los movimientos urbanos. Madrid: Editorial Alianza Universidad, (Primera edición en inglés, 1983).

Consejo Regional indígena del cauca www.cric-colombia.org Consultada en Diciembre de 2010.

Escobar, A. (2005). Más allá del Tercer Mundo. Globalización y Diferencia. Instituto Colombiano de Antropología, Bogotá: Universidad del Cauca.

Giddens, A. (1999). “Sección primera. Introducción”. Consecuencias de la Modernidad. Madrid: alianza Editorial. Págs. 11-59

González, J. (2008). "Nuevos repertorios tecnológicos y experiencia urbana de jóvenes: las implicaciones políticas de esta relación sociohistórica”. Documento inédito de trabajo, proyecto: "Cultura política, ciudad y ciberciudadanías", Grupo de Educación Popular, Universidad del Valle y Universidad Pedagógica Nacional, financiado por Colciencias. 
Gómez, R. y González J. (2004), "Pantallas reflexivas: reinventar la casa y domesticar las pantallas audiovisuales". Informe Final de Investigación, Universidad del Valle-CNTV, Imprenta Nacional, 2005.

González García, M., López Cerezo, J. y Luján López, J. (1996). “Imágenes de Tecnología". Ciencia, tecnología y sociedad: una introducción al estudio social de la ciencia y la tecnología. Madrid: Technos.

Guzmán, A. (2010). "Acción colectiva y región: el norte del Cauca y el sur del Valle (2006-2007)”. En: Castillo, L.; Guzmán, A.; Hernández, J.; Luna, M.; y Urrea, F. (Auts.), Etnicidad, acción colectiva y resistencia. El norte del Cauca y el sur del Valle a comienzos del siglo XXI, Cali: Programa Editorial de la Universidad del Valle, pp. 193-301.

Latour, B. (1998). "La tecnología es la sociedad hecha para que dure". En: Doménech Miquel y Tirado, F. (Comps.), Sociología simétrica. Ensayos sobre ciencia, tecnología y sociedad. Barcelona: Gedisa.

Lazzarato, M. (2006). Por una política menor. Acontecimiento y política en las sociedades de control, Madrid: Edición Traficantes de sueños. (Primera edición en francés 2004).

Mumford, L. (1987). Técnica y civilización. Madrid: Alianza editorial.

Revista Cambio (2008). No. 884, noviembre 04 de 2008, Bogotá.

Rheingold, H. (2002). Multitudes inteligentes. La próxima revolución social (smart mobs), Barcelona: Gedisa (Primer edición en inglés, 2002).

Rueda, R. (2008).”Cultura Política, Ciudad y Ciberciudadanías". Informe final del proyecto. Financiado por Colciencias y ejecutado por la Universidad Pedagógica Nacional y la Universidad del Valle.

Wajcman, J. (2006). El tecnofeminismo, Madrid: Ediciones Cátedra, Universidad de Valencia, Instituto de la Mujer.

Winner, L. (2001). ¿Los Artefactos Tienen Politica? Tomado de http://www. campus-oei.org/salactsi/winner.htm

Virilio, P. (1999). La bomba informática. Madrid: Cátedra. 